\title{
Mineral analysis of coastal sediment samples of Tuna, Gujarat, India
}

\author{
R. Ravisankar ${ }^{1}$, G. Senthilkumar ${ }^{2}$, S. Kiruba ${ }^{3}$, A. Chandrasekaran ${ }^{4}$ and Prince Prakash Jebakumar ${ }^{5}$ \\ ${ }^{1}$ PG \& Research Dept. of Physics, Govt. Arts College, Tiruvanamalai-606601, TN; ${ }^{2}$ Dept. of Physics, University \\ College of Engg., Arani-632317, TN; ${ }^{3}$ Dept. of Physics, St.Joseph's College of Engg., Chennai-119, TN \\ ${ }^{4}$ Department of Physics, Sacred Heart College, Thirupattur-635601, TN \\ ${ }^{5}$ National Institute of Ocean Technology, Pallikaranai, Chennai-601302, TN, India. \\ rrs_phy@rediffmaill.com; rrs_phy@yahoo.co.in; ravissn@gmail.com
}

\begin{abstract}
Qualitative analysis was carried out to determine the major and minor constituent minerals present in sediment samples collected at the coastal area of Tuna, Gujarat by FT-IR and XRD technique. From the IR absorption band or the locations of the different peaks, the minerals were identified with the available literature. In addition to the band positions, the sharpness or diffuseness of bands was helpful in the identification of mineral components. The IR study on sediment samples was highly useful in identifying the various minerals in sediments. Further, the representative sediment samples were analyzed by XRD technique to yield more information about the minerals. Both of these methods were non-destructive and can be used in the identification of mineralogical composition. These results confirmed that the applied techniques are relatively quicker and more reliable in mineral analysis.
\end{abstract}

Keywords: Sediment samples, mineral analysis, FT-IR, XRD technique.

\section{Introduction}

Sediments are principal carriers of the trace elements in the hydrosphere. Sediment particles are made up of materials derived from rock, soil, biological and anthropogenic inputs. The basic structural unit of inorganic sediment is silicate and aluminosilicate. Major components of sediments include clay, quartz, feldspars, various silicate minerals, gibbsite and calcium carbonate. They have been classified in a variety of ways according to different criteria such as their source, particle size and their composition. The size of sediments ranges from large size $(>256 \mathrm{~mm})$ called boulders down to $<2 \mu \mathrm{m}$ called clay. The more important size groupings are sand63 to $2000 \mu \mathrm{m}$; slit- 2 to $63 \mu \mathrm{m}$. The properties of sediment depend on its mineral composition, percentage of organic matter, sorption capacity for pollutants, porosity and particle size distribution. Properties of the sediments decide the concentration of the pollutant in the sediment. The mineral analysis is the prominent area of the research. It gives economic growth of the country. The radioactive minerals such as ilmenite, rutile, zirocm, garnet etc., will be used in the nuclear power reactor. Apart from the heavy minerals, the minerals like quartz, talc can be used for commercial application like quartz crystal and talc powder. The techniques such as thin section analysis, differential thermal analysis, X-ray diffraction studies, Mossbauer studies, magnetic methods, ultra-violet absorption studies and Infrared spectroscopic analysis are used for mineral analysis. Among the various techniques, IR spectroscopic technique is the best one for mineral analysis for its rapid, cheap, time consuming and non-destructive. In the present study an attempt has been made to investigate the qualitative minerals analysis of coastal sediment samples collected at Tuna, Gujarat using FT- IR and XRD techniques. Infrared spectroscopy as an analytical tool presents a lot of advantages as it is accurate, inexpensive and reliable. The necessary sample amount is in the sub milligram range and sampling procedure is simple. As a major advantage, infrared spectroscopy permits the identification of the changes in both crystalline and amorphous samples. Infrared spectroscopy has been utilized significantly in quantitative analysis in the minerals is less attempted.

The natural vibration frequencies of atoms in molecules and crystals fall in the infrared range. Certain frequencies corresponding to the energy levels of electrons in solids and in large molecules fall in the infrared. Infrared method is sensitive to short-range ordering or nearest-neighbor relation; while X-ray analysis is responsive to periodic arrangement of atoms, i.e., long-range order. Infrared spectroscopy has been widely used in the characterization of a large number of organic and inorganic compounds. Absorption of infrared energy by a mineral is associated with the vibrational and rotational motion of molecules within it.

Commonly the infrared analysis employs the group vibration concept to ascertain the presence or absence of various functional groups in the molecule. Certain chemical groups have characteristic absorption bands that are consistent among mineral containing groups. The spectra originate primarily from vibrational stretching and bending modes within molecules. The method offers a fingerprint for identification of molecular structures.

Empirical correlations of vibrating groups with specific observed absorption bands offer the possibility of chemical identification, and possibly quantitative analyses through intensity measurements. The band positions are
Research article

CIndian Society for Education and Environment (iSee)
"IR study of coastal sediments" http://www.indjst.org
Ravisankar et al. Indian J.Sci.Technol. 
noted in $\mu \mathrm{m}$ with corresponding wave number in $\mathrm{cm}^{-1}$. In the IR study of inorganic compounds and minerals, the spectra usually run through the range of 2.5 to $50 \mu \mathrm{m}$ (i.e., $4000-200 \mathrm{~cm}^{-1}$ ). On the other hand, UV-visible spectra generally cover 0.2 to $2.5 \mu \mathrm{m}$, termed as near IR (NIR), can be obtained in most of the modern UV-visible spectrometers.

This technique is versatile that it can be used both as a source of the physical parameters for crystal lattice determinations and as a means of eliciting purely empiliced qualitative relationships between specimens. It is a simple technique and is widely used in clay mineralogy, soil science and rock study.

The study area

Tuna is located on the northern shore of Gulf of Kachchh at the innermost tip in the open sea just at the entrance to the Kandla Creek. The location is in a tidal mudflat adjacent to the Nakthi creek typical to Gujarat coast. The tidal range in the location is about $6 \mathrm{~m}$. As of now, the location in Tuna is being used by KPT (Kandla port trust) as outer anchorage for ships waiting to be berthed in Kandla. Vast areas of salt pans occupy intertidal areas surrounding Tuna Island. The Tuna Island is approachable by kuchaa roads constructed by salt pan owners.

Mangroves are found in the intertidal areas of Tuna with a density of 1000 to 2000 plants $100 \mathrm{~m}^{2}$. These are found in hypersaline conditions with heights of about 1.5$2 \mathrm{~m}$ only. Mangroves are also found behind the proposed berthing areas. There are no corals found in this part of the Gulf of Kachchh. Seaweeds/sea grasses are absent or of low occurrence due to unsuitable conditions such as muddy substratum, high turbidity and high velocity currents.

\section{Geology of the study area}

The physiography is characterised by sandy plains and bare rocky hills. This area (Kachchh district, Gujarat) has very dry climate with very mild monsoon of about 340 $\mathrm{mm}$ (average rainfall), for about 30 days in a year. The soil of this region is highly saline with salt encrusted surface, which are incapable of supporting any vegetation. The soils of the Banni grasslands are classed as aridisols represented by solorthids and Camborthids. They are very deep, very poorly drained, fine loamy, calcareous with very severe salinity and slight erosion.

The soils of the Kachchh dominantly belong to aridisol and entisol orders. The soils of the hilly terrain are characterised by varying depths and textures. They are moderately alkaline and calcareous.

\section{Materials and methods \\ Sample Collection}

Sediment samples were collected using Peterson grab at all the designated locations during low tide. The stations were oriented to get the flesh out from Kandla creek, Nakthi creek and coastal in puts. The distance between each station falls about $1.7 \mathrm{kms}$. At each sample site, covering a sampling area of $1 \mathrm{~m}^{2}$, five wet samples were collected, each weighing about one kilogram. Among these five samples from a site, four were from the corners and one from the center. The other

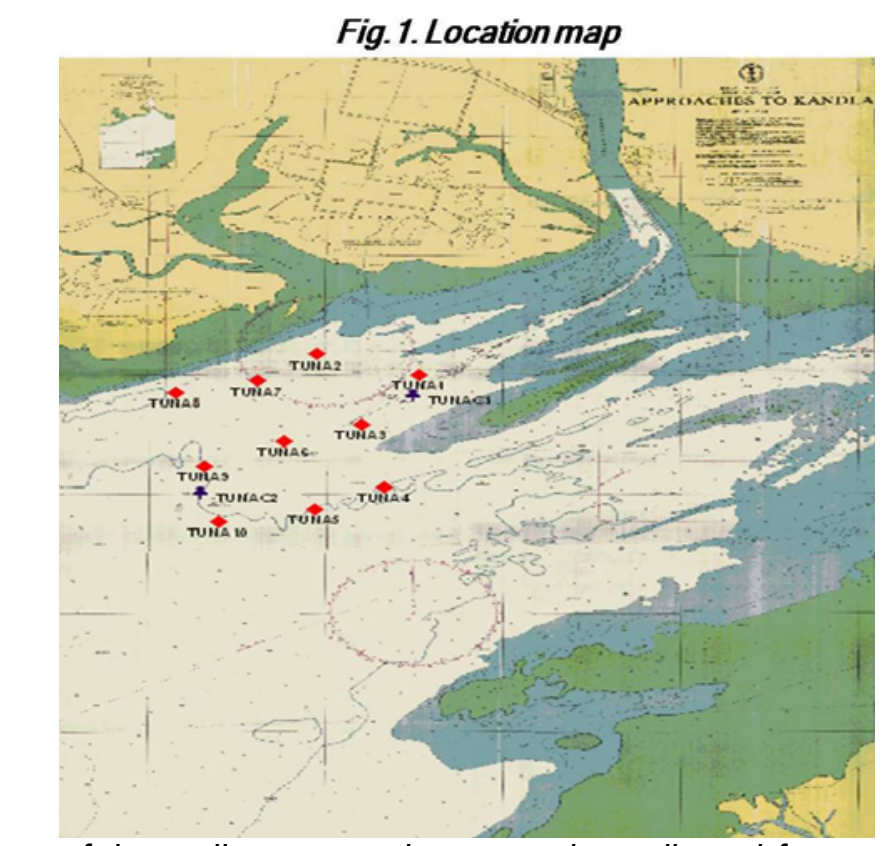

one of the sediment samples were also collected from a depth of $5 \mathrm{~cm}$ from the surface. The samples were placed in plastic pouches and transported to the laboratory. The map showing the study area and sample collection locations are indicated in Fig.1.The samples collected from different sites under study were labelled as $T_{1}-T_{10}$.

\section{Sample Preparation}

Sample of $2 \mathrm{mg}$ is mixed with $40 \mathrm{mg}$ of spectroscopic $\mathrm{KBr}$ in the ratio 1:20 using a mortar and pestle. Before mixing, necessary amount of $\mathrm{KBr}$ powder is dried at $120^{\circ} \mathrm{C}$ for six hours in an oven. Otherwise the broad spectral peak due to free $\mathrm{OH}$ will seriously affect the interpretation on the bound hydroxyls associated, with any of the minerals. The mineral sample was weighed in a microbalance and placed in a clean agate mortar along with the proper amount of dry $\mathrm{KBr}$ to prepare sample pellet. A pellet of $1 \mathrm{~mm}$ in thickness and $13 \mathrm{~mm}$ in diameter is prepared. A small camel's hair brush is used to transfer the mixture to the die for pressing the pellet. The die is cleaned with water and acetone, and dried before another pellet is prepared. This procedure is followed for the preparation of every pellet. The prepared pellet is preserved in a moisture free glass container before it is placed in a suitable sample holder and introduced in the infrared beam for analysis. For each site, five to six samples were collected and for each sample five to six pellet specimens were prepared.

Sample analysis

The ABB BOMEM 104.MB series available in Dr. Ceeal analytical laboratory, Thorappakkam, Chennai, Tamilnadu, India is made use of in the present work for recording the IR spectra of the samples at room temperature. The KBr pellet technique (1:20) pellets were 
followed for the mineral analysis. To provide a good characterization of a mineral by infrared spectroscopy, the spectrum should be recorded in the range of 4000$400 \mathrm{~cm}^{-1}$. Such coverage of range ensures that most of the useful vibrations active in the infrared will be included. The IR spectra were taken in the mid region of $4000-400$ $\mathrm{cm}^{-1}$. The instrument scans the spectra 16 times in $1 \mathrm{~min}$ and the resolution is $5 \mathrm{~cm}^{-1}$. This instrument is calibrated for its accuracy with the spectrum of a standard polystyrene film. Every time, before the spectrum of sample is obtained; the spectrum of the polystyrene film is taken and checked for the accuracy and transmittance. The best spectrum for each site was considered as a representative spectrum of the site. The typical IR spectrum is shown in Fig. 2.

Fig. 2. A typical FT-IR spectrum of sediment samples

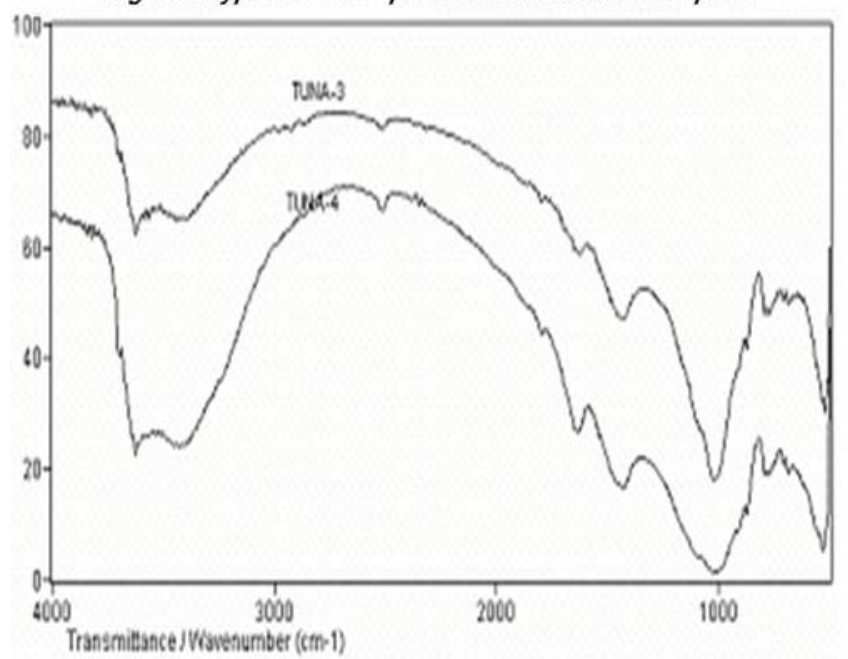

Results and discussions

The absorption frequencies of the peaks in the spectra of each site in wave number unit $\left(\mathrm{cm}^{-1}\right)$ are reported in Table 1. By comparing the observed frequencies with available literature, the minerals such as quartz, orthoclase, kaolinite, and montmorllinite have been identified. The mineralwise discussion is as follows:

Quartz

Quartz, one of world's most abundant crustal minerals and also important constituent of the Earth's crust. Chemically, it is silicon dioxide, $\mathrm{SiO}_{2}$. It is the second most abundant mineral in the Earth's crust. It occurs in crystals of the hexagonal prism commonly having the form of a six- sided prism terminating in a sixsided pyramid; the crystals are often distorted and twins are common. It occurs in hydrothermal veins and pegmatites. Quartz is a common constituent of granite, sandstone, limestone and many other igneous, sedimentary and metamorphic rocks.

It can be observed from the Table 2 that IR absorption bands appearing at or around 455$450,510-505,695-690,780-775$ and 800-795 $\mathrm{cm}^{-1}$ suggest the presence of quartz in the Research article OIndian Society for Education and Environment (iSee)
Table 1. Observed IR absorption frequencies of sediment samples of Tuna

\begin{tabular}{|c|c|}
\hline Sample No. & Observed IR absorption frequencies $\left(\mathrm{cm}^{-1}\right)$ \\
\hline T1 & $\begin{array}{l}408,471,508,525,535,630,713,776,875, \\
925,1025,1437,2516,3619 .\end{array}$ \\
\hline T2 & $\begin{array}{l}408,455,471,506,525,536,714,796,876, \\
1024,1438,3617 .\end{array}$ \\
\hline т3 & $\begin{array}{l}475,509,523,535,630,694,713,779,798, \\
874,922,1023,1437,1632,3441,3623 .\end{array}$ \\
\hline T4 & $\begin{array}{l}410,475,505,522,693,712,779,797,874, \\
923,1025,1436,1635,1796,2516,3448,3620 \text {, } \\
3695 .\end{array}$ \\
\hline T5 & $\begin{array}{l}455,509,523,540,630,694,713.779,797, \\
874,1025,1435,1632,2516,3435 .\end{array}$ \\
\hline T6 & $\begin{array}{l}407,476,506,525,694,713,778,796,874, \\
925,1025,1436,1635,1794,2520,3447,3619 .\end{array}$ \\
\hline $\mathrm{T7}$ & $\begin{array}{l}408,505,525,535,628,694,713,778,796, \\
874,920,1025,1635,1795,2518,3447,3619 .\end{array}$ \\
\hline T8 & $\begin{array}{l}454,477,505,524,535,626,694,713,778, \\
798,874,1025,1435,1635,1795,2518,3439, \\
3620,3690 .\end{array}$ \\
\hline T9 & $\begin{array}{l}410,508,525,625,694,713,779,797,874, \\
922,1021,1438,1636,1793,2518,3448,3623 .\end{array}$ \\
\hline T10 & $\begin{array}{l}455,475,505,525,540,626,694,713,779, \\
796,874,920,1025,1435,1633,1793,2520, \\
2926,3446,3621 .\end{array}$ \\
\hline
\end{tabular}

samples (Lyon, 1967; Chester \& Green, 1968; Farmer, 1974; Karr, 1975; Coates, 1977; Hlavay et al., 1978; Ghosh, 1978; Russell, 1987, Benedetto et al., 2002; Reig et al., 2002; Ramasamy et al., 2003, 2004, 2005; Ravisankar et al., 2006). The characteristic feature of quartz is a doublet appearing at or around 800 and 780 $\mathrm{cm}^{-1}$. Such a clear observation of a doublet was noticed in the samples $\left(T_{3}-T_{10}\right)$. The doublet, at 800 and $780 \mathrm{~cm}^{-1}$ though not convincingly appeared at the positions mentioned above and seems to have their positions slightly shifted towards the lower frequency region.

Table 2. IR absorption frequencies $\mathrm{cm}^{-1}$ of quartz present in the samples

\begin{tabular}{|c|c|c|c|c|c|c|c|c|c|}
\hline T1 & T2 & T3 & T4 & T5 & T6 & T7 & T8 & T9 & T10 \\
\hline- & 455 & - & - & 455 & - & - & 454 & - & 455 \\
\hline & - & 694 & 693 & 694 & 694 & 694 & 694 & 694 & 694 \\
\hline 776 & - & 779 & 779 & 779 & 778 & 778 & 778 & 779 & 779 \\
\hline- & 796 & 798 & 797 & 797 & 796 & 796 & 798 & 797 & 796 \\
\hline
\end{tabular}

Any slight shift in the peak may be due to impurities, crystal defects or isomorphous substitutions (Yariv \& Mendelovici, 1979). This has also been confirmed by many workers (Turner, 1953; Tuddenham \& Lyon, 1960; Chester \& Green, 1968; White, 1971; Farmer, 1974; Hlavay et al., 1978; Ganguly \& Banerjee, 1985; Boruah et al., 1999). The doublet at 800 and $780 \mathrm{~cm}^{-1}$ may be used for the identification and quantitative estimation of quartz.

Table 3. IR absorption frequencies $\mathrm{cm}^{-1}$ of albite \& orthoclase* present in the samples

\begin{tabular}{|c|c|c|c|c|c|c|c|c|c|}
\hline T1 & T2 & T3 & T4 & T5 & T6 & T7 & T8 & T9 & T10 \\
\hline 408 & 408 & - & 410 & - & 407 & 408 & - & 410 & - \\
\hline $535^{*}$ & $536^{*}$ & $535^{*}$ & - & $540^{*}$ & - & $535^{*}$ & $535^{*}$ & - & $540^{*}$ \\
\hline $630^{*}$ & - & $630^{*}$ & - & $630^{*}$ & - & $628^{*}$ & $626^{*}$ & $625^{*}$ & $626^{*}$ \\
\hline
\end{tabular}

"IR study of coastal sediments" http://www.indjst.org
Ravisankar et al. Indian J.Sci.Technol. 
Usually, the intensities of the peaks of the doublet are not comparable. Hence in the samples $\left(T_{1} \& T_{2}\right)$ the $800 \mathrm{~cm}^{-1}$ peak is either absent or very weak. For the same samples other than this doublet, two more peaks were additionally observed at or around $695-690 \mathrm{~cm}^{-1}$ and $455-450 \mathrm{~cm}^{-1}$, which are also characteristic of quartz.

Table 4. IR absorption frequencies $\mathrm{cm}^{-7}$ of calcite present in the samples

\begin{tabular}{|c|c|c|c|c|c|c|c|c|c|}
\hline T1 & T2 & T3 & T4 & T5 & T6 & T7 & T8 & T9 & T10 \\
\hline 713 & 714 & 713 & 712 & 713 & 713 & 713 & 713 & 713 & 713 \\
\hline 875 & 875 & 874 & 874 & 874 & 874 & 874 & 874 & 874 & 874 \\
\hline 1437 & 1438 & 1437 & 1436 & 1435 & 1436 & - & 1435 & 1438 & 1435 \\
\hline
\end{tabular}

For every sample a minimum of two to maximum of four peaks are obtained. The pattern of absorption in quartz can be explained by ascribing the $455 \mathrm{~cm}^{-1}$ region ( $\mathrm{Si}-\mathrm{O}$ asymmetrical bending vibrations), the bands in the region $690 \mathrm{~cm}^{-1}$ (Si-O symmetrical bending vibrations), the bands in the region $780 \mathrm{~cm}^{-1}$ (Si-O symmetrical stretching vibrations) and $800 \mathrm{~cm}^{-1}$ (Si-O symmetrical stretching vibrations).

The crystallinity index of quartz using the intensities of symmetrical stretching mode lying at $800-795 \mathrm{~cm}^{-1}$ and the symmetrical bending mode at $700-695 \mathrm{~cm}^{-1}$ has been calculated by many workers. The crystallinity can be defined as the fraction of crystalline materials in a mixture of crystalline and non-crystalline materials. It is otherwise called as degree of disorder. If the crystallinity is minimum, then the minerals are said to be in disordered state. If it is maximum then the minerals are considered to be in ordered state. The crystallinity of quartz may give clear indication on the crystalline forms of other minerals also. If this crystallinity is maximum then the other minerals may also be expected to be equally in wellcrystallized state.

It may be essential to find out the crystallinity of quartz in the samples. The $695 \mathrm{~cm}^{-1}$ peak, present in most of the samples gives useful information on the nature of mineral with regard to the structural stability. The intensity of this peak gives the type of crystallinity. The symmetrical bending vibrations of Si-O group obtained at $695 \mathrm{~cm}^{-1}$ is more useful to find whether it is crystalline or amorphous. In the amorphous state, $695 \mathrm{~cm}^{-1}$ peak will be missing. This is a well known fact (Hlavay et al., 1978). As the $695 \mathrm{~cm}^{-1}$ peak is exhibited by the spectra of all the samples (expect $T_{1} \& T_{2}$ ) the quartz mineral in these samples are in crystalline form.

Feldspar

Feldspar is the name of an important group of rock forming minerals which make up perhaps as much as $60 \%$ of the Earth's crust. The general formula for feldspars can be written as $\mathrm{WZ}_{4} \mathrm{O}_{8}$ in which $\mathrm{W}$ may be a $\mathrm{Na}, \mathrm{K}, \mathrm{Ca}$ and/or $\mathrm{Ba}$ and $\mathrm{Z}$ is $\mathrm{Si}$ and/or $\mathrm{Al}$, the Si:Al ratio ranging from $3: 1$ to $1: 1$. Since all feldspars contain a certain minimum amount of $\mathrm{Al}$, the general formula may be somewhat more specifically stated as WAI (AI, Si) $\mathrm{Si}_{2} \mathrm{O}_{8}$, the variable (AI, Si) being balanced by variation in the proportions of univalent and bivalent
Vol. 3 No. 7 (July 2010) ISSN: 0974- 6846
Ramasamy et al, 2003, 2004, 2005, Xu et al., 2001; Ramasan et al., 2006). The peaks in the range of $540-535 \mathrm{~cm}^{-1}$ and 630 $625 \mathrm{~cm}^{-1}$ for orthoclase and weak shoulder at 410-405 $\mathrm{cm}^{-1}$ for albite were observed in the samples. The peak pertaining to the range $540-535 \mathrm{~cm}^{-1}$ is due to $\mathrm{Si}-\mathrm{O}$ asymmetrical bending vibrations and $630-625 \mathrm{~cm}^{-1}$ is due to Al-O-coordination vibrations (Ramasamy et al., 2004). Carbonate class

The carbonates consist of those minerals containing the anion $\left(\mathrm{CO}_{3}\right)^{2-}$ and include calcite and aragonite (both calcium carbonate), dolomite (magnesium/calcium carbonate) and siderite (iron carbonate). Carbonates are commonly deposited in marine settings when the shells of dead planktonic life settle and accumulate on the sea floor. Carbonates are also found in evaporitic setting (e.g. the Great Salt Lake) and also in Karst regions, where the dissolution and reprecipitation of carbonates leads to the formation of caves, stalactites and stalagmites. The carbonate class includes the nitrate and borate minerals.

It can be observed from the Table 4, that IR absorption peaks appear at 715-710, 875-870, 1440-1435, 18001795 and $2520-2515 \mathrm{~cm}^{-1}$ and are assigned to calcite. The IR absorption peaks of calcite are reported by many workers (Hunt \& Turner, 1953, Adler \& Kerr 1962, 1963; Chester \& Elderfield, 1967; Karr, 1975; Ghosh, 1978; Bottcher et al., 1997; Lopez et al., 2000; Senthil Kumar et al., 2001; Benedetto et al., 2002; Reig et al., 2002; Ramasamy et al., 2003, 2005; Ravisankar et al., 2006).

According to the frequency assignments reported by Herzberg (1945) for carbonate minerals the different modes of vibrations are a symmetric stretching, $\mathrm{v}_{1}$; an out-of-plane bending, $\quad \mathrm{v}_{2} ; \quad \mathrm{a}$ doubly degenerate asymmetric stretching, $\mathrm{v}_{3}$; and a doubly degenerate planar bending $\mathrm{v}_{4}$. But the symmetric oscillation represented by $v_{1}$ is reported to be infrared inactive and hence only three fundamentals are ordinarily encountered. These have been recorded for various calcite group minerals in the regions of absorption at approximately $1430 \mathrm{~cm}^{-1}\left(v_{3}\right), \quad 909-833 \mathrm{~cm}^{-1}\left(v_{2}\right)$ and 769$666 \mathrm{~cm}^{-1}\left(\mathrm{v}_{4}\right)$. In the present investigation, the calcite spectra show major proportion having the absorption bands at approximately $1435 \mathrm{~cm}^{-1}, 874 \mathrm{~cm}^{-1}$ and $713 \mathrm{~cm}^{-1}$ and minor bands at $1796 \mathrm{~cm}^{-1}$ and $2516 \mathrm{~cm}^{-1}$.

The IR spectra of calcite and dolomite are characterized by bands at $711 \mathrm{~cm}^{-1}$ and $727 \mathrm{~cm}^{-1}$ 
respectively. These bands appear unperturbed and sharp with varying intensity depending on the concentration of these minerals. But in the present study the $727 \mathrm{~cm}^{-1}$ peak is completely absent in all the samples showing the absence of dolomite. If dolomite were present, then phase change would have occurred at lower temperature. Clay minerals

Kaolinite: Kaolinite is a mineral with the chemical composition $\mathrm{Al}_{2} \mathrm{Si}_{2} \mathrm{O}_{5}(\mathrm{OH})_{4}$. It is layered silicate mineral, with one tetrahedral sheet linked through oxygen molecules to one octahedral sheet of alumina octahedral. It is known as china clay and kaolin. It is softy, earthy, usually white mineral, produced by chemical weathering of feldspars. Due to extremely fine nature (finer than slit), it is mixed with water and transported in tanks as a liquid slurry. It is used in ceramics, medicines, bricks, paper, as a food additive, in toothpaste, and in cosmetics. A recent use is as a specially formulated spray to fruits, vegetables and other vegetation to repel or deter insect damage. A traditional use is to soothe an upset stomach, similar to the way parrots (and later, humans) in South America originally used it.

Table 5. IR absorption frequencies $\mathrm{cm}^{-1}$ of Kaolinite, Montmorillonite* \& Illite ${ }^{* *}$ present in the samples

\begin{tabular}{|c|c|c|c|c|c|c|c|c|c|}
\hline T1 & T2 & T3 & T4 & T5 & T6 & T7 & T8 & T9 & T10 \\
\hline 471 & 471 & 475 & 475 & - & 476 & - & 477 & - & 475 \\
\hline $525^{\star}$ & $525^{*}$ & $523^{*}$ & $522^{*}$ & $523^{*}$ & $525^{\star}$ & $525^{*}$ & $524^{*}$ & $525^{\star}$ & $525^{*}$ \\
\hline $925^{\star *}$ & - & $922^{* *}$ & $923^{* *}$ & - & $925^{* *}$ & $920^{* *}$ & $922^{* *}$ & - & $920^{* *}$ \\
\hline 1025 & 1024 & 1023 & 1025 & 1025 & 1025 & 1025 & 1025 & 1021 & $1025^{*}$ \\
\hline - & - & $163222^{*}$ & $1635^{*}$ & $1632^{*}$ & $1635^{*}$ & $1635^{*}$ & $1635^{*}$ & $1635^{*}$ & $1633^{*}$ \\
\hline- & - & $3441^{* *}$ & $3448^{*}$ & $3435^{*}$ & $3447^{*}$ & $3447^{*}$ & $3439 *$ & $3448^{*}$ & $3446^{*}$ \\
\hline 3619 & 3617 & 3623 & 3620 & - & 3619 & 3619 & 3620 & 3623 & 3621 \\
\hline- & - & - & 3695 & - & - & - & 3690 & - & - \\
\hline
\end{tabular}

From the Table 5, the presence of the absorption bands at $3690,3620,1030$ and $475 \mathrm{~cm}^{-1}$ indicate kaolinite (white, 1971; Karr, 1974; Hlavay et al., 1978; Russell, 1987; Crowley \& Vergo, 1988; Clark et al., 1990; Summer, 1995; Gustafsson et al., 1999; Madejova \&
Komadel, 2001; Xu et al., 2001; Benedetto et al., 2002; Ramasamy et al., 2004, 2005; Ko \& Chu, 2005; Ravisankar et al., 2006).

Kaolinite shows a characteristic IR absorption sequence in the range of $3700-3600 \mathrm{~cm}^{-1}$. These absorbances correspond to stretching vibrations of inner surface $\mathrm{OHs} 3696 \mathrm{~cm}^{-1}$ and inner $\mathrm{OH} 3620 \mathrm{~cm}^{-1}$. Absorbance at 1105 and $1034 \mathrm{~cm}^{-1}$ are attributed to antisymmetric Si-O-Si stretching, whereas those at $1018 \mathrm{~cm}^{-1}$ are attributed to stretching of an $\mathrm{O}$ atom bound to both $\mathrm{Si}$ and tetrahedral Al (Summer, 1995). According to Russell (1987), if four peaks are observed in the region of 3697$3620 \mathrm{~cm}^{-1}$, the mineral is said to be ordered state. However, in the present study only two peaks are observed at 3690 and $3620 \mathrm{~cm}^{-1}$. This suggests the mineral is in disordered state.

Montmorilinite: is a very soft phyllosilicate mineral that typically forms in microscopic crystals, forming clay. Chemically it is hydrated sodium calcium aluminum magnesium silicate hydroxide $(\mathrm{Na}, \mathrm{Ca}) \times(\mathrm{Al}, \mathrm{Mg})_{2}$ $\left(\mathrm{Si}_{4} \mathrm{O}_{10}\right)(\mathrm{OH})_{2} \cdot \mathrm{nH}_{2} \mathrm{O}$. The exact ratio of cations varies with source. It is a member of the smectite family i.e., 2:1 clay, meaning that it has 2 tetrahedral sheets sandwiching a central octahedral sheet. It is the main constituent of the volcanic ash weathering product, bentonite. It is used in the oil drilling industry as a component of drilling mud, making the water slurry viscous which helps in keeping the drill head cool and removing drill debris. It is also used as a soil additive to hold soil water in drought prone soils, to the construction of earthen dams and levees and to prevent the leakage of fluids. It is used as a component of foundry sand and as a desicant to remove moisture from air and gases. It is also used therapeutically on humans.

From the Table 5, the presence of peaks at 3450$3445,1635-1630$ and $525-520 \mathrm{~cm}^{-1}$ in all the samples

Table 6. Band assignments for different minerals of sediment samples of Tuna

\begin{tabular}{|c|r|l|l|}
\hline Minerals & Frequency $\left(\mathrm{cm}^{-1}\right)$ & Tentative assignments & References \\
\hline \multirow{3}{*}{ Quartz } & $458 \& 455$ & $\mathrm{Si}$ - O asymmetrical bending vibration & \\
& $695-693$ & $\mathrm{Si}-$ O symmetrical bending vibration & Hlavay et al., (1978); Coates (1977) \\
& 875 & $\mathrm{Si}$ - O symmetrical stretching vibration & \\
\hline \multirow{3}{*}{ Feldpar } & $540-533$ & $\mathrm{Si}-$ O symmetrical stretching vibration & Coates(1977) White(1971) \\
& $589-586$ & $\mathrm{O}-\mathrm{Si}(\mathrm{Al})$ - O bending vibration & Zhang et al., (1996); Coates (1977) \\
& $644-640$ & $\mathrm{Al}-\mathrm{O}-$ Co-ordination vibration & Hlavay et al., (1977); Coates(1977) \\
Kaolinte & 908 & Al (OH) vibrations & Russell, (1987); Summer (1995) \\
& $1035-1030$ & Si-O Stretching & \\
\hline
\end{tabular}

Research article

(CIndian Society for Education and Environment (iSee)
"IR study of coastal sediments" http://www.indjst.org
Ravisankar et al. Indian J.Sci.Technol. 
indicates the presence of montmorillonite. The most distinguishing feature of the montmorillonite spectrum is the broad absorption band that ranges from 3300 to 3500 $\mathrm{cm}^{-1}$. This band typically centered around $3400 \mathrm{~cm}^{-1}$ may be due to $\mathrm{H}-\mathrm{O}-\mathrm{H}$ stretching of water molecules present in the interlayer region of montmorillonite (Summer, 1995). The peak pertaining to the range $1635-1630 \mathrm{~cm}^{-}$ ${ }^{1}$ due to $\mathrm{OH}$ deformation of water and $530-525 \mathrm{~cm}^{-1}$ is due to Al-O-Si-deformation (Madejova \& Komadel, 2001).

Illite: is a non-expanding, micaceous mineral. It is a phyllosilicate or layered silicate. Structurally illite is quite similar to muscovite or serticite with slightly more silicon, magnesium iron and water and slightly less tetrahedral aluminum and interlayer potassium. It occurs as an alteration product of muscovite and feldspar in weathering and hydrothermal environments. It is common in sediments, soils and argillanceous sedimentary rocks as well as in some low grade metamorptic rocks. Infrared features of illite are rarely diagnostic because it is so variable in chemical composition. The presence of peak around $920 \mathrm{~cm}^{-1}$ in the samples is attributed to illite, it is reported in Table-5 (Farmer, 1979; Balasubramanian, 1984; summer, 1995; Clark et al., 1990; Post \& Noble, 1993; Xu et al., 2001; Benedetto et al., 2002). The band assignment for the different minerals is reported in Table 6.

\section{$\mathrm{XRD}$ analysis}

Samples for X-ray powder diffraction (XRD) studies were packed in shallow cavities in glass slides to minimize preferred orientation. The $X$-ray patterns of soil samples were recorded at room temperature by using $X$ ray diffractometer (D500, Siemens) having a curved graphite crystal diffracted monochromator, with a source of CuK radiation and $\mathrm{Nal}(\mathrm{TI})$ scintillation detector from material science division (MSD), Indira Gandhi Centre for

\section{Fig. 3. Typical X-ray diffractrogram of sedimentsamples}

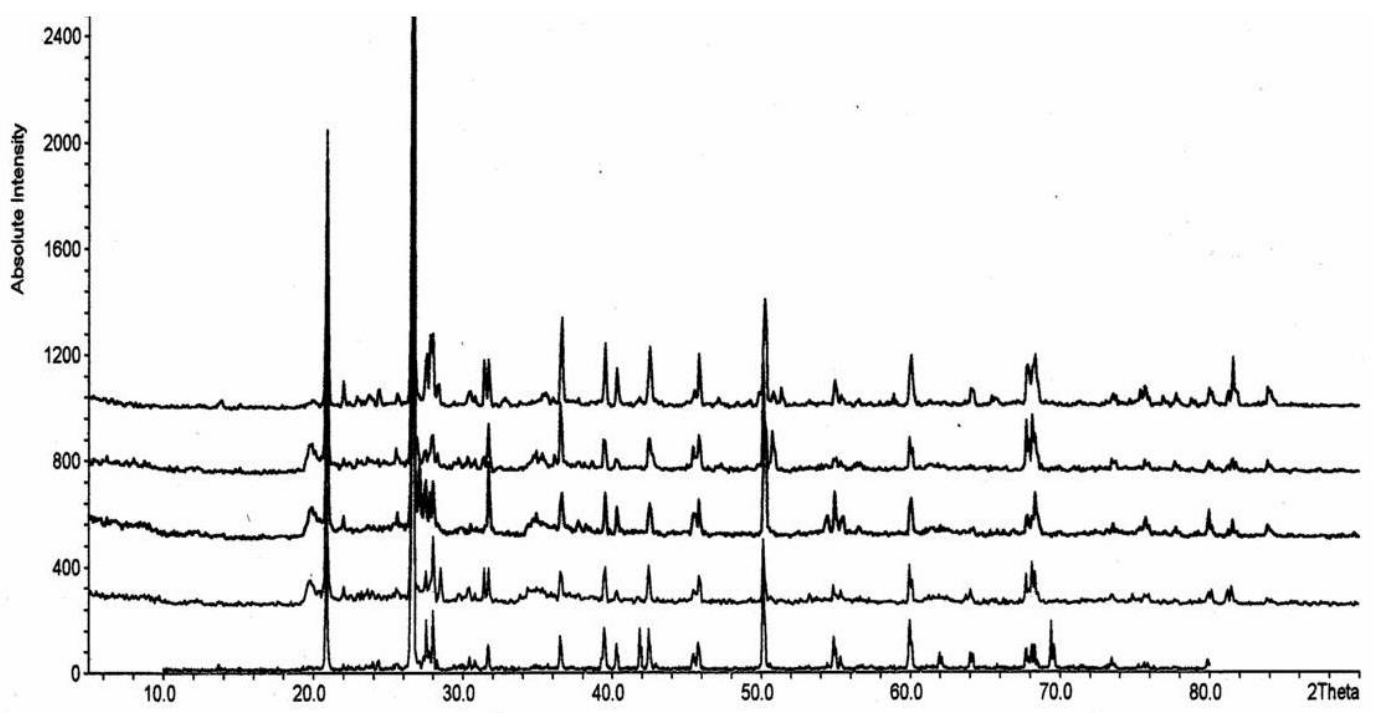

determined with the standard interpretation procedures of $X R D$. Major mineral in the studied sample is quartz. Typical X-ray diffractrogram of sediment samples are shown in Fig. 3.

\section{Mineral wise analysis}

Qualitative mineralogy of the coastal sediment samples is determined with the standard interpretation procedures of XRD. The mineral wise discussion is as follows

Quartz: Quartz is ubiquitous and forms one of the most abundant mineral in all the samples. It is identified by the distinctive reflection at $4.254 \mathrm{~A}^{\circ}, 3.343 \mathrm{~A}^{\circ}, 2.456 \mathrm{~A}^{\circ}$, $2.281 \mathrm{~A}^{\circ}, 2.127 \mathrm{~A}^{\circ}, 1.817 \mathrm{~A}^{\circ}, 1.541 \mathrm{~A}^{\circ} 1.382 \mathrm{~A}^{\circ}, 1.374 \mathrm{~A}^{\circ}$ and $1.371 \mathrm{~A}^{\circ}$.

Feldspar: The feldspar mineral is invariably present in all samples. Albite is identified by basal reflection at 4.030 $A^{\circ}, 3.780 A^{\circ}, 3.684 A^{\circ}, 3.663 A^{\circ}, 3.196 A^{\circ}$ and $2.933 A^{\circ}$. The basal reflection at $4.222 \mathrm{~A}^{\circ}, 3.777 \mathrm{~A}^{\circ}, 3.470 \mathrm{~A}^{\circ}$, $3.310 \mathrm{~A}^{\circ}, 3.290 \mathrm{~A}^{\circ} 3.240 \mathrm{~A}^{\circ}, 2.992 \mathrm{~A}^{\circ}, 2.901 \mathrm{~A}^{\circ}$ and $2.571 \mathrm{~A}^{\circ}$ indicated the presence of orthoclase.

Gypsum: It is identified by the basal reflections at 4.283 $\mathrm{A}^{\circ}, 3.065 \mathrm{~A}^{\circ}$ and $2.873 \mathrm{~A}^{\circ}$.

Calcite: It is identified distinct reflections in the d spacing of $3.035 \mathrm{~A}^{\circ}, 2.495 \mathrm{~A}^{\circ}, 2.285 \mathrm{~A}^{\circ}, 2.095 \mathrm{~A}^{\circ}$ and $1.875 \mathrm{~A}^{\circ}$.

Rutile: The d spacing of $4.283 \mathrm{~A}^{\circ}, 2.487 \mathrm{~A}^{\circ}$ and $1.687 \mathrm{~A}^{\circ}$ indicated the presence of rutile in the samples.

Garnet: Alamdine garnet is seen in the sample by the presence of the reflection with the $d$ values of $2.881 \mathrm{~A}^{\circ}$, $2.572 \mathrm{~A}^{\circ}$ and $1.540 \mathrm{~A}^{\circ}$.

\section{Conclusion}

The qualitative identification of minerals in coastal sediment samples was carried out by FT-IR and XRD techniques. The IR analyses of sediment samples from different locations of Tuna indicate the presence of quartz, orthoclase, albite, kaolinte, montmorillonite and calcite. Among the different minerals quartz is present invariably in all the samples. Hence it is considered to be main or major constituent of the sample and feldspar is also present in different compositions i.e., albite and orthoclase. The crystalline nature of the mineral is also attempted using quartz and discussed. The XRD analyses of the selected samples show presence of quartz, albite, orthoclase, gypsum, calcite, rutile and garnet. Among these minerals quartz showed Atomic Research (IGCAR), Kalpakkam, Tamil Nadu, large number of peaks in the diffractrogram. This India. Qualitative mineralogy of the soil samples is indicates that quartz is the most abundant mineral in the 
sediment samples and is supported by the IR studies. The combined method of FT-IR and XRD showed that it is a powerful technique for mineral analysis in geological samples.

\section{References}

1. Adler HH and Kerr PF (1962) Infrared spectra symmetry and structure relations of some carbonate minerals. Am. Min. 48, 839-853.

2. Adler HH and Kerr PF (1963) Infrared study of Aragonite and calcite. Am. Min. 47,700-717.

3. Bottcher ME, Gehlken PL and Steele, DF (1997) Characterization of inorganic and biogenic magnesian calcites by Fourier Transform infrared spectroscopy. Sol. State lonics. 101, 1379-1385.

4. Boruah RK, Neog AK, Borah PC and Baruah GD (1999) Petrographic study of silica bearing rocks from Assam, India. Ind. J. Eng. Mat. Sci. 6, 338-341.

5. Benedetto GED, Laviano R, Sabbatini $L$ and Zambonin PG (2002) Infrared spectroscopy in the mineralogical characterization of ancient pottery. J. Cul. Her. 3, 177-186.

6. Chester R and Elderfield H (1967) The application of infrared absorption spectroscopy to carbonate mineralogy. Sedimentology. 9, 5-21.

7. Chester R and Green RN (1968) The infrared determination of quartz in sediments and sedimentary rocks. Chem. Geo. 3, 199-212.

8. Karr C Jr (1974) Infrared and Raman spectroscopy of lunar and terrestrial Minerals, Academic press, Newyork, pp325358.

9. Clark RN, King TVV, Kiejwa M, Swayze GA and Verge N (1990) High spectral resolution reflectance spectra of minerals. J. Geophys. Res. 95, 12653-12657.

10. Coates JP (1977) The IR analysis of Quartz and Asbestos, Nelioth Offset Ltd., Chesham, England.

11. Crowley JK and Vergo N (1988) Near-infrared reflectance of mixtures of kaolin group minerals; use in clay. Clay Clay Minerals. 36, 310-316.

12. Farmer VC (1974) The IR Spectra of minerals, mineralogical society, London, 42, 308-320.

13. Farmer VC (1979) Infrared spectroscopy, Data hand book for clay naterials and other non metallic minerals, Ed.Van Olphen and Fripait, $1^{\text {st }}$ Ed., Pergaman press, Oxford, London. pp: 285-337.

14. Ganguly J and Banerjee BK (1985) Appraisal of infrared spectra of isolated clay fractions from different soil profiles. Trans. Ind. Cer. Soc. 26, 44-46.

15. Ghosh, S.N (1978) Infrared spectra of some selected minerals, rocks and products. J. Mat. Sci. 13, 1877-1886.

16. Herzberg G (1945) Molecular spectra and molecular structure II. Infrared and Raman spectra of polyatomic molecules, D.Van Nostrant Co., Inc., New York, p178.

17. Hlavay J, Jonas K, Elek S and Inczedy J (1978) Characterization of the particle size and the crystallinity of certain minerals by infrared spectrophotometry and other instrumental methods-II. Investigation on quartz and feldspar. Clay Minerals. 26, 139-143.

18. Hunt JM and Turner DS (1953) Determination of mineral constituents of rocks by infrared spectroscopy. Anal. Chem. 25, 1169-1174.

19. Ko TH and Chu H (2005) Spectroscopic study on sorption of hydrogen sulfide by means of red soil. Spectro. Chimica. Acta. Part-A, 61, 2253-2259.
20. Lopez MCB, Martinez-Alono and Tascon JMD (2000) Mineral matter characterization in olivine stones by joint use of LTA, XRD, FT-IR and SEM-EDX. App. Spect. 54, 1712 1715.

21. Lyon RJP (1967) Infrared absorption spectroscopy, physical methods in determinative mineralogy. Zussman $\mathrm{J}$ (Ed.) Academic Press, NY. pp: 371-403.

22. Madejova and Komadel (2001) Baseline studies of the clay minerals society source clays: Infrared Methods. Clay Minerals. 49, 410-432.

23. Neog AK, Boruah RK, Sahu OP, Borah PC, Ahmed W and Boruah GD (1999) XRD and IR of Deopani clay. Asian. Chem. Letts. 3, 172-175.

24. Post JL and Noble PN (1993) The near infrared combination band frequencies of dioctahadral smectities, micas and illites. Clay Minerals. 41, 639-644.

25. Ramasamy $\mathrm{V}$, Dheenathayalu M, Ponnusamy $\mathrm{V}$, Murgesan S and Mullainathan S (2003) Characterization of quartz and feldspars in white granites. J. Curr. Sci. 3(1), 181-185.

26. Ramasamy V, Murgesan S and Mullainathan S (2004) Characterization of minerals and relative disturbtion of quartz in Cavery river sediments from Tamil Nadu, India-A FT-IR study. Bull. Pure Appl. Sci. 23F (1-2), 1-7.

27. Ramasamy V, Murgesan S and Mullainathan S (2004) Fourier Transform infrared analysis of some sediments from Palaru river, Tamil Nadu, India. J. Curr. Sci. 5(2), 599-601.

28. Ramasamy V, Murgesan S and Mullainathan S (2005) Distribution and characterization of minerals in Cauvery river sediments by grain size analysis-A new approach by FT-IR study. Ind. Mineralogist. 39(2), 91-107.

29. Ravisankar R, Rajalakshmi A and Manikandan (2006) Mineral characterization of soil samples in and around saltfield area, Kelambakkam, Tamil Nadu, India. Acta Ciencia Indica. 32(3), 341-346.

30. Reig FB, Adelankndo JVG and Moreno MCM (2002) FT-IR Quantitative analysis of calcium carbonate (Calcite) and Silica (Quartz) mixtures using the constant ratio method; application to geological samples. Talanta. 58, 811-815.

31. Russell JD (1987) Infrared methods, a hand book of determinative methods in clay mineralogy, Wilson MJ (Ed.), Blackie \& Son Ltd, NY. pp:11-67.

32. Senthil Kumar P, Parthasarathy G, Sharma DS, Srinivasan $R$ and Krishnamurthy $P$ (2001) Mineralogical and geochemical study on carbonate veins of Salem-Attur fault zone, Southern India: evidence for carbonate affinity. J. Geo. Soc. Ind. 58, 15-20.

33. Tuddenham WM and Lyon RJP (1960) Infrared techniques in the identification and measurements of minerals. Anal. Chem. 32, 1630-1634.

34. Summer ME (1995) Hand book of soil science, University of Georgia, Boca Raton Hondor press, New York.

35. White JL (1971) Interpretation of infrared spectra of soil minerals. Soil Sci. 112, 22-67.

36. Xu Z, Cornilsen BC, Popko DC, Penning WD, Wood JR and Hwang JY (2001) Quantitative mineral analysis by FT-IR spectroscopy. Int. J. Vib. Spec. 5, 4-6.

37. Yariv SH and Mendelovici E (1979) The effects of degree of crystallinity on the infrared spectrum of hematite. App. Spectroscopy. 33, 410-411.
Research article

CIndian Society for Education and Environment (iSee)
"IR study of coastal sediments" http://www.indjst.org
Ravisankar et al. Indian J.Sci.Technol. 